\title{
Business Models and the Internet of Things (Extended Abstract)
}

\author{
Elgar Fleisch $^{1}$, Markus Weinberger ${ }^{2(\bowtie)}$, and Felix Wortmann ${ }^{1,3}$ \\ ${ }^{1}$ ETH Zürich and University of St. Gallen, Dufourstrasse 40a, \\ 9000 St. Gallen, Zürich, Switzerland \\ efleisch@ethz.ch, felix.wortmann@unisg.ch \\ ${ }^{2}$ Bosch Software Innovations GmbH, Dufourstrasse 40a, \\ 9000 St. Gallen, Zürich, Switzerland \\ markus.weinberger@bosch-si.com \\ 3 University of St. Gallen, Dufourstrasse 40a, \\ 9000 St. Gallen, Zürich, Switzerland
}

\begin{abstract}
In this extended abstract we aim on providing an overview on business models based on the Internet of Things for assisting companies that are currently focused on non-digital industries. In the first section the role of the Internet as an innovation driver for business models is reflected, secondly it is shown how business model patterns from digital industries are becoming relevant to physical industries as well. General business model logic patterns for the Internet of Things are shown and the challenges of implementing such patterns in hybrid business models are addressed.
\end{abstract}

\section{The Influence of the Internet on Business Models to Date}

In Today's market information technology (IT) has impacted business model innovation. In [4] more than 300 cases of companies have been studied, that broke with the established logic in their industries and in the process permanently changed it. Gillette, IKEA, Nespresso and Pixar are well-known examples of such companies. Out of these case studies a set of 55 business model patterns could be identified. A business model pattern is defined "as a definite configuration of four core elements (who are the customers? What is being sold? How is it produced? How is revenue earned?) that have proven successful in different companies and industries."

It is striking that since the 1990 s, IT has been extremely significant in many case studies, even though there continue to be business model patterns that manage to transform an industry without IT. On the one hand, this is not surprising since IT first became widely used throughout the business world in the 1990s. On the other hand, the concentration of IT-driven cases is impressive. A large share of the newer case studies relies in particular on digital business model patterns.

Many of the IT-influenced business model patterns - regardless of the technology wave from which they emerged - follow three overarching trends:

This article has previously been published as a Whitepaper of the Bosch Internet of Things and Services Lab, a Cooperation of HSG and Bosch (2014) - www.iot-lab.ch. 
- Integration of users and customers. IT enables companies to increasingly integrate their customers in their value-creation chain. In other words, IT allows companies to delegate some tasks to their customers. Examples can be found in the User Designed, E-Commerce, Open Source (content) and Mass Customization business model patterns.

- Service orientation. Run time services and/or after-sales digital contact with customers are on the rise. Using IT-based services, IT allows companies to maintain and make use of customer relationships even after the sale. Exemplary business model patterns for this include Rent instead of Buy, Subscription, Freemium, Razor and Blade and Add on.

- Core competence analytics. Precise collection and analysis of transaction and use data are increasingly valuable and represent a key skill for product design, pricing, and sales structuring. Examples can be found in the Subscription, Flat Rate, Freemium, Pay per Use and Performance-based Contracting business model patterns.

IT is used today to upgrade value in business model patterns. When the Hidden Revenue pattern is applied by companies like Google or Facebook, however, which are part of digital industries, IT is by definition constitutive. IT not only revives old business model patterns and generates new business model patterns; it has also facilitated the emergence of an entirely new digital industry and redefined old business model patterns in that industry.

Many digital business model patterns, such as Freemium, have been applied exclusively in the digital world until now. In manufacturing industries, the Internet has mainly been used to simplify processes - and thus reduce costs while increasing quality and the variety offered. The Internet has been responsible for big breakthroughs in digital industries, as Google, Facebook, PayPal, eBay, YouTube, and others prove.

\section{The Economic Power of the Internet of Things}

This section outlines the formative power of the Internet of Things within the economy. A broader and more well-grounded analysis of the economic perspective on the Internet of Things can be found in $[1,2]$.

The digital world - and that includes its various industries - differs in multiple dimensions from the physical world and its industries, for instance in the areas of marginal costs in production, transport, and storage, in transport and production speeds, and in the ability to abstract and simulate.

Digitalization leads to high resolution management because the marginal costs of measuring (in the control process) and the actuating elements (in the controller) are almost zero, while interventions can be made with almost the speed of light.

The Internet of Things is now applying this logic step by step to the physical world. It represents the vision that every object and location in the physical world can become part of the Internet. Objects and locations are generally equipped with mini-computers so they become smart objects that can take in information about their environment and communicate with the Internet and other smart objects. These minicomputers are usually barely visible or completely invisible, so the physical dimension of the object remains people's most important interface. 
Smart things are hybrids, composed of elements from both the physical and digital worlds. That means that, when used, they unite the principles of both worlds and in doing so, introduce high resolution management into the physical world, too [1].

Should a fastening equipment manufacturer operating an electronic Kanban system at its customers' plants provide information on the consumption to his customers free of charge or use the freemium model? Or service-for-pay integrated with physical delivery right from the start? And who owns the data? The customer whose warehouse is the source of the data, or the supplier; after all, he owns the smart containers that generate the data. Can and should the data - anonymized, across the entire customer base - reveal valuable, real-time developments in the industry and be capitalized as part of the Leverage Customer Data business model pattern? Whichever is chosen, the Freemium and Leverage Customer Data models are both examples of how business model patterns that have been confined to digital industries can suddenly become relevant for classic physical industries.

\section{Business Model Patterns in the Internet of Things}

The application-driven goal of this article is to derive well-grounded assistance, both theoretical and practical, for developing Internet of Things business models. These models should be inspiring and provided on a level of abstraction that will facilitate their application across industries, while remaining concrete enough to be actionable for innovators in business and society at large.

To accomplish this, we analyzed the 55 business model patterns from Gassmann [4] and many Internet of Things applications with regard to their value-creating steps and high resolution management. It is the latter that embody both the opportunities and limitations of the Internet of Things' technical capacities. The results of this analysis can be represented as six-components for business model patterns for the Internet of Things: Physical Freemium, Digital Add-on, Digital Lock-in, Product as Point of Sales, Object Self-Service, Remote Usage and Condition Monitoring. Based on their power and their kinship - all of them facilitate digital services for physical products - we merge them all together in a new business model pattern specific to the Internet of Things, Digitally Charged Products. On the other hand, the concept of Sensor as a Service is so novel and so powerful that we suggest that it is itself a new business model pattern. Further details on these components and new business model patterns can be found in [3].

\section{Entrepreneurial Challenges in Implementing Internet of Things Business Models}

Generating new ideas is not the biggest hurdle in establishing a new business model. The capabilities of an Internet of Things reignite the discussion regarding the optimal mix of product versus service in a business model.

One feature of the Internet of Things is the fact that the service portion of the business models outlined here is always digital in nature. This has two consequences: 
First, the theory and practice of service orientation must be critically examined and expanded as needed against the backdrop of the characteristics of digital services. Second, digitalization that extends into the product itself (in contrast to digital support in the value-creation process) must of necessity lead to an additional service orientation.

The differing characteristics of physical and digital products are particularly noticeable in product development. In a world where a bug can be repaired with an update at almost no cost, even in an installed base running in the millions, and where right from the start high growth is required due to network effects, speed, early customer contact, and aesthetics are of utmost importance in development. In the hardware business, however, and in the world of embedded computing as well, other terms apply. Here, for example, an error in a product that has already been sold usually results in an extremely costly, image-damaging recall action. These differences conditioned by technology and economics have meant that divergent cultures arose in hardware compared to those governing Internet software departments and have shaped putatively incompatible organizational units.

Small units that can and must operate in the tradition of lean startups [5] are advantageous in addressing another challenge. Their leanness itself forces them to work on development together within a network of partners - which include their customers. This implies not only a lead user approach [6] but encompasses an entire ecosystem as facilitator. In the digital world, the one who brings the most developers to its platform wins. In most instances, hybrid solutions mean that the party offering them must have access to data that is constantly generated from application of the solution. This is new for classic production companies and brings with it both many opportunities as well as risks.

\section{Summary and Outlook}

The goal of this essay is to inspire innovators from business and society at large to develop business models leveraging the Internet of Things. It analyzes the role that the Internet has played in business models to date, documents the specific economic energy of the Internet of Things, and derives from that the general product/service logic serving as the foundation for specific components and patterns of Internet of Things business models. Finally, it indicates some of the key challenges involved in its implementation that will confront in particular companies with a successful history in manufacturing industries.

Maybe this essay raised more questions than it answers. But hopefully some can now be more specifically formulated. The Internet of Things remains an academically and economically fascinating and rewarding phenomenon.

Acknowledgements. The Bosch Internet of Things and Services Lab provided major funding to HSG for this project. We thank Prof. Oliver Gassmann, Ass. Prof. Karolin Frankenberger, Kristina Flüchter and Stefanie Turber for invaluable discussions and for their support. 


\section{References}

1. What is the Internet of Things? An Economic Perspective, Auto-ID Labs White Paper WPBIZAPP-053, ETZ Zürich \& University of St. Gallen, January 2010. http://www.im.ethz.ch/ education/HS10/AUTOIDLABS-WP-BIZAPP-53.pdf

2. Fleisch, E., Christ, O., Dierkes, M.: Die betriebswirtschaftliche Vision des Internets der Dinge. In: Fleisch, E., Friedemann, M. (eds.): Das Internet der Dinge, pp. 3-37. Springer, Berlin (2005)

3. Fleisch, E., Weinberger, M., Wortmann, F.: Business Models and the Internet of Things, Whitepaper of the Bosch Internet of Things and Services Lab, a Cooperation of HSG and Bosch (2014). www.iot-lab.ch

4. Gassmann, O., Frankenberger, K., Csik, M.: Geschäftsmodelle entwickeln: 55 innovative Konzepte mit dem St. Galler Business Model Navigator. Hanser Verlag, Munich (2013)

5. Ries, E.: The lean startup: How Today's Entrepreneurs Use Continuous Innovation to Create Radically Successful Businesses. Crown Business (2011)

6. von Hippel, E.: Lead users. A source of novel product concepts. Manage. Sci. 32, 791-805 (1986) 


\section{黛 Springer}

http://www.springer.com/978-3-319-16545-5

Interoperability and Open-Source Solutions for the Internet of Things

International Workshop, FP7 OpenloT Project, Held in

Conjunction with SoftCOM 2014, Split, Croatia, September 18, 2014, Invited Papers

Podnar Zarko, I.; Pripužić, K.; Serrano, M. (Eds.)

2015, X, 183 p. 72 illus., Softcover

ISBN: $978-3-319-16545-5$ 